\title{
A PERSISTÊNCIA DO TROTE UNIVERSITÁRIO E DA VIOLÊNCIA NO CONTEXTO EDUCACIONAL
}

\author{
Carlos Eduardo Ramos \\ CAObe LUCAS Rodrigues de SOUSA \\ Universidade Federal de Roraima (UFRR), Boa Vista, Roraima, Brasil
}

Resumo: $\mathrm{O}$ objetivo deste artigo é compreender como ocorrem os trotes universitários na Universidade Federal de Roraima (UFRR). Orienta-se pela perspectiva da Teoria Crítica da Sociedade. Para a coleta de dados, foram realizadas observações em trotes dos cursos de Medicina e Engenharia Civil e entrevistas com alunos que já participaram do trote. Foi possível constatar que o trote busca, em certa medida, se adequar ao modelo tradicional (marcado por situações vexatórias, violência psicológica, etc.), e os motivos pelos quais essa prática é defendida estão principalmente vinculados à adesão do indivíduo ao grupo. Os resultados da pesquisa permitiram a produção de um enredamento entre questões que, superficialmente, parecem não ter ligações diretas, mas que não podem ser ignoradas para se compreender a cultura do trote no contexto da universidade.

Palavas-chave: Trote. Universidade. Violência. Grupos.

INTRODUÇÃO

$O$ ingresso no ensino superior, principalmente nas instituições públicas, costuma ser coroado pela realização do trote universitário, que atua como uma iniciação do indivíduo em um determinado grupo. Como aponta Vasconcelos (1993), o trote, em sua forma tradicional, consiste na prática de atitudes vexatórias de flagelo, destacando-se, dentre as mais comuns, o 
corte de cabelos, a indução à embriaguez e a pintura do corpo com tintas, graxas, etc. No entanto, a violência presente no trote não se limita àquela que se efetiva nos corpos. A humilhação presente no trote pode também ser de outra natureza, da qual destacamos a violência psicológica.

De acordo com Zuin (2011), a história do trote se confunde com a história da própria universidade, tendo em vista que as primeiras universidades na Europa já serviam de cenário para práticas dos mais variados atos de violência física e psicológica para com novos estudantes. Em Paris, no ano de 1342, foi registrado o primeiro trote, protagonizado por alunos franceses e alemães. A principal característica desse evento foi que as agressões eram realizadas de acordo com as diferenças nacionais. Assim, serviu como um desdobramento para a rixa entre os países, que se transfigurou na forma da clássica rixa entre calouros e veteranos.

É comum que os calouros sejam tratados como inferiores por alunos veteranos, como se fossem menos dignos de respeito por serem recém-chegados ao local (VASCONCELOS, 1993). O trote permite a criação de um terreno livre para manifestações de violência que se caracterizam, principalmente, pela opressão e pela dominação entre os envolvidos. As pessoas que realizam essas práticas geralmente sustentam suas atitudes sob a leitura do trote como uma tradição de importância que deve ser perpetuada em nome da integração e da socialização dos colegas universitários (ZUIN, 2011). Porém, há sempre o perigo em tentar justificar qualquer ação de violência em nome de tradições, sobretudo quando ocorrem casos de violência que se projetam para além do microcosmo universitário, devido a suas impactantes consequências, como mortes, em alguns casos.

Diante disto, este artigo procura compreender o trote no contexto da Universidade Federal de Roraima (UFRR), lançando um olhar sobre seus aspectos de violência e os modos como se manifesta. Entende-se que existem outras formas de recepção de calouros como os trotes solidários, culturais, ecológicos, dentre outros, que podem ser denominados como trotes alternativos (VASCONCELOS, 1993). No entanto, é importante salientar que aqui a modalidade de trote referida é a tradicional. Isso não significa que mesmo os trotes alternativos não contenham elementos de violência, uma vez que podem não prescindir da hierarquia entre calouros e veteranos, por exemplo.

A UFRR é a primeira instituição federal de ensino superior do estado de Roraima. Localiza-se na cidade de Boa Vista, no bairro Aeroporto, e foi implantada no final de 1989, de acordo com a Lei $n^{\circ} 7.364$, de 12 de dezembro de 1985. Atualmente, conta com mais de oito mil alunos nos cursos 
de educação básica, nível técnico, graduação e pós-graduação. Destacase nacionalmente por ter sido a primeira a ofertar, a partir da criação do Instituto Insikiran de Formação Superior Indígena, cursos específicos para alunos indígenas e oferecer formação intercultural para professores indígenas (RISTOFF; GIOLO, 2006).

Sabe-se que muitos dos cursos da UFRR promovem algum tipo de trote, sendo uma das principais atividades o pedágio nas avenidas. Nesse procedimento, os calouros são levados pelos veteranos até os semáforos mais próximos e, geralmente sujos de tintas e aos gritos dos veteranos, pedem dinheiro às pessoas que, em seus automóveis, estão paradas nos semáforos. $O$ dinheiro recolhido é utilizado, via de regra, para a realização de uma festa que é conhecida como "Calourada". Ali promove-se a socialização de estudantes de todos os semestres. Em alguns casos, o convite para a festa é comercializado.

A cidade de Boa Vista não é estranha a alguns casos ocorridos durante o trote que alcançaram proporções de extrema violência. Em uma das "Calouradas", realizada em 2014 por alunos do curso de Engenharia Civil, dois calouros - sendo um deles menor de idade - foram hospitalizados após ambos entrarem em estado de coma alcoólico em um jogo organizado por veteranos, cujo vencedor seria aquele que bebesse mais. ${ }^{1}$ Esse episódio fez com que a questão ganhasse foco tanto nas discussões populares quanto em meios de comunicação locais, resultando em uma manifestação pública de repúdio ${ }^{2}$ ao trote por parte da administração superior da universidade.

Apesar disso, tais acontecimentos não foram suficientes para intimidar os promotores desse rito na universidade, que persistem mesmo após toda a polêmica. Talvez este seja um indicativo de que o trote na instituição em questão é suportado por um forte tradicionalismo ou, pelo menos, uma forte reprodução dessa tradição. Principalmente quando se considera a possibilidade de que as "Calouradas" são tidas pelos organizadores do trote como uma estratégia eficaz para produzir o senso de coletividade necessário para uma boa integração dos alunos do curso.

Diante dessas considerações, destacamos duas principais perguntas: por que, apesar de toda a regressão que o acompanha, o trote persiste no contexto universitário? E como sua compreensão, no contexto da UFRR, pode contribuir para essa reflexão? Dentre outras razões, este artigo tem o objetivo de investigar essa manifestação, que pode incorrer em atos de barbárie, bem como as condições que geram tais regressões. E, partindo do pensamento de Adorno (2003), compreender como a tendência geral da sociedade administrada contribui para a falsa formação de sujeitos com traços sádicos reprimidos. 
TROTE, UNIVERSIDADE E VIOLÊNCIA

Para iniciar esta discussão, parte-se da constatação de que, ao contrário do que é sugerido no senso comum, a universidade não é uma instituição puramente neutra e isolada da sociedade e, dessa forma, é acometida por profundas contradições do mundo social (TRAGTENBERG, 2004). Dissociar a universidade do mundo socioeconômico em que está inserida contribui para estabelecer a ilusão de que a produção de conhecimento científico e a formação de profissionais no meio acadêmico são desvinculadas de interesses econômicos e da perpetuação de uma brutalidade intrínseca ao modo de produção capitalista.

No plano ideal, poderíamos atribuir à universidade as funções de promoção da emancipação por meio do conhecimento, por um lado, e a capacitação dos estudantes para a inserção no mundo do trabalho, por outro. Entretanto, essas funções não são facilmente conciliáveis, pois, entre a finalidade da formação e as características do mundo do trabalho, existem contradições profundas. No caso específico da UFRR, seu estatuto (2003) apresenta a ética, a liberdade cultural, política e social, a defesa dos direitos humanos e o incentivo à paz como alguns de seus princípios fundamentais. Entretanto, manifestações de barbárie que ocorrem em seu espaço e no de outras universidades reverberam contradições deixadas por essas promessas não cumpridas. Como explica Zuin (2002, p.244), esses acontecimentos servem para "desvelar a essência de uma cultura cujo progresso das forças produtivas exige a concomitante regressão das capacidades físicas e espirituais de seus produtores".

Sabe-se o quanto o trote contribui para consolidar uma hierarquia entre veteranos e calouros. De acordo com Adorno (2008), é um antigo elemento da ideologia burguesa que cada indivíduo nutra um interesse em se considerar superior aos demais, reproduzindo a hierarquia indispensável ao modo de vida no capitalismo. O ambiente universitário não escapa desse imperativo quando serve de cenário para rituais que manifestam de maneira cabal o quanto é primordial que se estabeleça uma relação de superioridade entre os membros da instituição.

Como aponta Saviani (2012), o modelo pedagógico tecnicista prioriza a manutenção sistemática e administrativa regida pela lógica prática de eficiência. As instituições de ensino são geridas sob uma ótica puramente técnica, o que coloca quaisquer perspectivas subjetivas em segundo plano, inclusive na relação professor-aluno. Essa manifestação de valores do modo de produção capitalista na universidade se evidencia na medida em que se 
percebe o quanto a subjetividade dos discentes e dos docentes é moldada de acordo com as demandas do mercado. Como afirma Tragtenberg (2004, p. 14), "a universidade reproduz o modo de produção capitalista dominante não apenas pela ideologia que transmite, mas pelos servos que ela forma".

Ao se pensar a relação entre a ciência e a universidade, tendo em vista os significados subjetivos do aluno também na qualidade de agente científico, cabe pensar a respeito do que postula Horkheimer (1991), em seu artigo "Teoria Tradicional e Teoria Crítica":

A aparente autonomia nos processos de trabalho, cujo decorrer se pensa provir de uma essência interior ao seu objeto, corresponde à ilusão de liberdade dos sujeitos econômicos na sociedade burguesa. Mesmo nos cálculos mais complicados, eles são expoentes do mecanismo social invisível, embora creiam agir segundo suas decisões individuais (HORKHEIMER, 1991, p. 37).

Dessa forma, encontramos sujeitos impossibilitados de emanciparemse dos objetivos determinantes que os cercam, tornando-se mera força operacional, sem a capacidade de agirem de maneira democrática e cidadã, mesmo quando se inserem na sociedade assumindo o papel de cientistas que, a princípio, deveriam estar atentos para as armadilhas da ideologia e pautar-se de acordo com os direitos humanos.

\section{A FRAGILIZAÇÃO DO EGO E O PROCESSO DE ADESÃO AOS GRUPOS}

Freud (1978) observa que o ser humano é atormentado por uma dificuldade de ser e permanecer em um estado de felicidade plena e associa essa condição com as renúncias necessárias para que a vida na sociedade seja possível. Com isso, as pulsões sexuais e agressivas passam a ser censuradas pelo superego, instância psíquica responsável por imprimir os valores morais da sociedade no ego. Bueno (2005, p. 38) reforça que o elemento que garante a existência da civilização "[...] sobrevive como seu antagonista secreto, no nível inconsciente, sob a forma do ressentimento permanente contra a civilização". Esse contrato firmado com a sociedade implica a aceitação de que o indivíduo deve ser inserido em uma ordem social e econômica já existente, porém, quando essa formação não lhe garante consciência crítica, o indivíduo tende a dirigir esse ódio, gerado pelas frustrações mantidas no inconsciente, às minorias.

Cabe aqui uma analogia com as situações percebidas nos trotes, uma vez que, como aponta Tragtenberg (2004), o universitário está submetido ao professor por meio de uma relação de poder marcada pela necessidade de um sistema rigoroso e burocrático de avaliação, além de outras dificuldades 
relacionadas às contradições vividas cotidianamente, porém ignoradas. Em geral, entende-se que a universidade é assombrada por uma violência institucional velada, mas que se manifesta quase como um sintoma de algo da ordem do inconsciente, em fenômenos tais como o trote.

Para compreender melhor os diversos processos referentes a esse tipo de comportamento, cabe retornar ao assunto da formação psíquica apresentada pela psicanálise, e discutida por Horkheimer e Adorno (1978), relacionando sua constituição a partir da tensão entre a conservação ideológica do modelo tradicional de família e sua superação, no sentido de atribuir a essa instituição um lugar socialmente definido. Os autores apresentam o anacronismo de uma instituição que se mantém feudal (baseada no princípio do "sangue") em uma sociedade pautada no sistema de troca. Ainda assim, cumpre a importante função de adaptar seus membros à sociedade, por meio de uma identificação com a autoridade, "[...] idealizada como ética do trabalho, que substituiu funcionalmente o domínio imediato do senhor sobre os servos da época medieval" (HORKHEIMER; ADORNO, 1978, p. 137). A família exige a figura de um pai imponente e provedor, para que o filho possa superar o momento da autoridade e da heteronomia. Mas, como aponta Bueno (2005), essa figura paterna é exclusivamente característica do século XIX e foi enfraquecida pelas inúmeras transmutações econômicas e sociais da época.

O resultado desse processo é a produção de indivíduos com egos frágeis, que não confrontaram a imagem paterna idealizada com sua imagem real porque sequer a construíram. Os indivíduos cuja personalidade se estrutura dessa maneira tendem a apresentar maior suscetibilidade ao fascismo, pois se identificam cegamente com o líder. Adorno (2003, p. 37) relaciona essa frágil formação aos processos grupais, ao afirmar que esses sujeitos "[...] no fundo dispõem só de um eu fraco, necessitando, para se compensarem, da identificação com grandes coletivos e da cobertura proporcionada pelos mesmos".

O perigo que se oculta no trote é o potencial da ação coletiva em anular a consciência individual, especialmente sob as condições aqui discutidas. Afinal:

A brutalidade de hábitos tais como os trotes de qualquer ordem, ou quaisquer outros costumes desse tipo, é precursora imediata da violência nazista. Não foi por acaso que os nazistas enalteceram e cultivaram tais barbaridades com o nome de "costumes" (ADORNO, 2003, p. 128). 
O francês Gustave Le Bon defendia que os grupos têm uma mente grupal própria, suprimindo a individualidade daqueles que participam do grupo. Freud (1977), em sua leitura acerca dos grupos, considerou estes como constituídos por enlaces libidinais, enfatizando a existência de processos psíquicos individuais essenciais para a constituição do grupo. Freud aponta para a existência de grupos menos efêmeros como as multidões estudadas por Le Bon, pensando em pertencimentos coletivos contínuos - como classe, raça, religião, etc - e inferindo que pertencer a um grupo não implica necessariamente o fim da individualidade. Porém, entende que, assim como na hipnose, a imersão no grupo pode acarretar a substituição do ideal do ego pelo objeto, indicando um certo caráter de regressão e de redução da consciência.

Silva (2010) reconhece uma sociedade em que os progressos da racionalidade tecnológica incentivaram o surgimento de uma disparidade na constituição psíquica dos indivíduos, entre a representação de si e a capacidade de perceber a realidade objetiva de maneira clara e distinta. Desse modo, a cultura de racionalidade instrumental produz e necessita de sujeitos cuja sustentação psíquica só pode ocorrer através de mecanismos como o narcisismo e o sadomasoquismo. Esse processo influencia diretamente no comprometimento da capacidade de pensamento crítico que possa desafiar o status quo.

Ainda de acordo com o mesmo autor, o mundo administrado é marcado pela frieza e pelo individualismo exacerbado, originados das relações de produção do capitalismo. Essas configurações estruturais e econômicas revelam-se no campo subjetivo dos indivíduos por meio de traços da personalidade, como indiferença, apatia e até mesmo crueldade. Todas essas maneiras de se relacionar com os outros e com o mundo estão ligadas a uma cultura instrumental que nutre as pulsões destrutivas e egoístas e que resultam na dinâmica sadomasoquista como um paradigma de vínculos na sociedade administrada. Portanto, o sadomasoquismo, apesar de ser compreendido como um tipo de perversão sexual, pode ser entendido também como uma das "formas-padrão de associação da sexualidade dessublimada sob a orientação da sociedade repressiva com a organização técnica da cultura" (SILVA, 2010, p. 138).

Acreditamos que o diagnóstico da sociedade que pode contribuir para a compreensão do trote e das relações nas universidades é permeado por questões relativas à fragilidade do ego; ao desvanecimento da autoridade no seio familiar; a processos de adesão irracionais a grupos; ao enlace entre a lógica de mercado e o processo de troca no processo de constituição dos 
indivíduos, e à dinâmica sadomasoquista. Partindo dessas noções, é possível apresentar o modo como o trote universitário se configura na UFRR e seus desdobramentos nas relações entre os alunos.

MÉTOdo

Este artigo é resultado de um subprojeto de Iniciação Científica realizado em 2017. ${ }^{3}$ A pesquisa foi desenvolvida a partir de entrevistas com calouros e veteranos e tem caráter qualitativo. Após o levantamento bibliográfico, os dados foram coletados por meio de observações assistemáticas e entrevistas abertas. Para a escolha dos entrevistados, não houve um critério específico de seleção, contudo, foram entrevistados somente calouros e veteranos que já participaram do trote. Foi realizada a observação de dois trotes, o de Medicina e o de Engenharia Elétrica.

Em relação aos procedimentos de análise, os dados coletados foram sistematizados e categorizados tendo como base o referencial teórico, embora a elaboração das categorias não se limite à teoria. Esta é fundamental para orientar o processo, mas não deve se sobrepor ao objeto e a suas particularidades. A análise e a discussão foram pautadas na perspectiva da Teoria Crítica da Sociedade. Triviños (1987, p. 117) aponta que esse enfoque parte da necessidade de refletir sobre os dados de realidade "[...] para transformá-los em processos contextuais e dinâmicos complexos". O objetivo principal não foi o de reafirmar uma teoria previamente estabelecida, mas tornar possível que particularidades do objeto sejam apropriadas e relacionadas com elementos gerais presentes na teoria. Em outras palavras, a reflexão foi construída na relação entre a teoria e o material empírico coletado, considerando elementos do particular e do universal.

\section{RESULTADOS E DISCUSSÃO}

A princípio cabe apontar que, a partir das observações e entrevistas, se mostraram bastante evidentes práticas de violência intensamente marcadas pela hierarquização entre os membros da instituição durante a realização do trote. A lógica do trote tradicional se repete e se consolida ano após ano no contexto pesquisado. No entanto, para além do que se esperava a respeito dessa dinâmica, inúmeros outros pontos também surgiram e serão expostos a seguir. Para facilitar a exposição das reflexões, foi feita uma divisão em quatro tópicos. O primeiro deles consiste em uma breve caracterização dos entrevistados para auxiliar na apresentação dos resultados. 


\section{CARActerizaÇÃo dos entREVISTAdos}

Os entrevistados foram Élcio, Mauro, Paulo e Paloma (nomes fictícios). Élcio tem 23 anos, cursa Engenharia Elétrica, ingressou na UFRR no primeiro semestre de 2012 e nasceu na cidade de Boa Vista. É da segunda turma do curso, então participou de todos os trotes realizados no seu curso. Mauro tem 23 anos, cursa Medicina, ingressou na universidade no primeiro semestre de 2016 e nasceu na cidade de Boa Vista. Participou de dois trotes, um como calouro e outro como veterano. Paulo tem 19 anos, ingressou no primeiro semestre de 2017, cursa Psicologia e nasceu em Boa Vista. Fazia o mesmo curso em uma universidade particular e participou somente de um trote, como calouro, na UFRR. Paloma tem 20 anos, também cursa Psicologia, ingressou no primeiro semestre de 2016, tem 20 anos e nasceu na Paraíba.

\section{TROTE, RESSENTIMENTO E RELAÇÕES HIERÁRQUICAS NA UNIVERSIDADE}

Nas quatro entrevistas realizadas, os sentidos mais comuns atribuídos ao trote relacionam-se com a função de diversão e integração entre os estudantes. Como defende Élcio: "É só um momento de diversão mesmo. É um dia que a gente foge da rotina. [...] É um evento em que as pessoas vão se conhecer". Mauro enfatiza a importância do trote, reconhecendo o caráter ritualístico do evento. "É uma forma de ritual. Que é bom para quem participa, desde que seja de forma saudável, né? É claro que tem gente que é totalmente idiota e estúpida e acaba extrapolando esse encontro saudável". Para Paulo, o trote serve para "quebrar aquele gelo, para que a própria turma possa interagir um com o outro. Não só entre a turma em si, mas os cursandos em geral". Para Paloma, "parece um rito de passagem, quando vocêpassa no vestibular, vocêtem que ter um trote. Daíchega aqui, todo mundo tem trote, todo mundo fica pintado e sujo. Então você espera que isso aconteça com você também". Evidencia-se, então, a partir dos sentidos atribuídos pelos sujeitos entrevistados, que o trote assume primeiramente a função de integrar, divertir os membros do grupo e simbolizar um importante momento de transição na vida dos universitários.

Para além dessa leitura superficial trazida pelos entrevistados, em que o caráter benevolente do trote se sobressai, nota-se que, em alguns momentos das entrevistas, contradições emergem, indicando que o trote pode também exercer a função contrária à integração, pois carrega também elementos de segregação, quando, por exemplo, Paloma relata uma experiência desagradável em seu trote: 
Na verdade eu acho que as pessoas pensam que o trote é tipo uma humiIhaçãozinha que você tem que passar por isso. Não me senti humilhada, humilhada é uma palavra forte. Mas eu não me senti confortável em comer cebola, por exemplo. A galera ficava "Come! Deixa de frescura". Eu particularmente odeio cebola, eu não consigo comer cebola. Eu comi, óbvio. Passei o resto da tarde enjoada. Era cebola doce. Mas eu fiz, a turma queria, né?

Ou quando Élcio afirma que o trote fica "um pouco mais pesado" ano após ano.

[...] Aquela tinta lá que não sai nunca. O pessoal tava misturando com cola [...] pra poder misturar mais ainda. Por isso que eu decidi não participar né? Eu acompanhei, iniciei o trote e tudo mais, mas quando eu vi que a brincadeira tava ficando um pouco pesada demais, eu já me abstive, fiquei só observando mesmo.

Dada a ambivalência de sentidos encontrada, é necessário aprofundar o olhar sobre o fenômeno e buscar compreender o que está por trás do que os entrevistados manifestam. É possível perceber um ponto bastante expoente nas entrevistas: em todas elas, há um forte senso de descontentamento em relação à universidade. Pode haver, desse modo, uma possível relação entre a violência institucional e aquela que percebemos no trote. Élcio, na fala que segue, relata a conturbada relação aluno-professor de seu curso e denuncia uma lógica excludente e violenta, na qual o curso e a universidade parecem estar contra o aluno, o que resulta em uma elevada reprovação e uma elevada evasão no curso. Seguem também os depoimentos de Paulo e Mauro, que também narram as inquietações que sentem no contexto em questão.

A gente tá em uma realidade que é a seguinte. Entra quarenta pessoas em uma turma, mas se formar três pessoas no período correto já é suficiente. $E$ muitos professores a mentalidade deles é essa. “Eu não estou aqui pra formar 30 alunos, eu estou aqui pra formar três ou cinco, se os outros desistirem, paciência" (Élcio).

A questão do horário é algo bastante ruim né? Isso de não poder trabalhar, de ter uma carga horária excessiva [...] pelo fato do meu curso ser integral, mas acho que lá na frente vai valer a pena né? Se não eu não estaria apto a estar aqui me sujeitando a essa carga horária. Poderia estar em uma instituição privada que foi de onde eu vim (Paulo).

Eu me sinto sobrecarregada. É uma sensação péssima, chegar o final de semana e você não pegar no material e você se sentir mal. Mal mesmo porque você não estudou. Sendo que a gente passa todos os dias aqui. Não tem um dia livre. A gente não sente que é justo a forma de avaliação dos 
professores. É um sofrimento. Tem vezes que você vem e você vê que tá todo mundo muito baixo astral, eu acredito que não deveria ser assim (Paloma).

Há, então, um evidente descontentamento com a universidade, que perpassa pelo âmbito social, já que se trata da categoria estudantil que, em maior ou menor grau, sente-se oprimida por diversos fatores. A relação professor-aluno, como é o caso de Élcio; os arranjos políticos, sociais, culturais e institucionais, como é o caso de Paloma, e a carga horária excessiva, como reclamam Paulo e Paloma, podem ser alguns dos motivos que contribuem para esse estado de descontentamento. Este poderia conter um forte potencial de mobilização política, visto que essa percepção pode ser o primeiro passo para que emerja algum processo de consciência, que aponta para possibilidades de reivindicações e melhorias para os alunos. No entanto, o trote pode servir como válvula de escape para essas insatisfações, na forma de violência hierarquizada, tal como na violência existente na relação professor-aluno. Há também uma outra face desse sentimento negativo para com a universidade, que seria um tipo de angústia oculta, que pode ser representada pela palavra ressentimento.

Como aponta Bueno (2005), o ressentimento é um conceito de extremo valor para a psicanálise, pois é tido como um estado imanente no indivíduo civilizado, devido às inúmeras renúncias instintuais necessárias para a vida em sociedade. Porém, em uma sociedade em que se enfatizam a competitividade e o mérito por desempenho, "esse ressentimento manifestase como uma hostilidade sombria, uma ameaça permanente contra a vida civilizada" (BUENO, 2005, p. 39).

Élcio narra o surgimento de um certo conformismo em relação ao contexto em que ele está inserido, o que funcionaria como uma renúncia de seus anseios individuais. Estas podem gerar um sentimento de ressentimento, pois significam a abdicação de algo. Caso não haja recompensa para essas abdicações, o indivíduo sente um mal-estar, que é provavelmente um dos principais propulsores do trote. Outro fator bastante identificado nas entrevistas é esse sentimento de sobrecarga vinculado às relações de hierarquia e poder próprias do funcionamento institucional, como já apontado nas citações de Élcio. Sem dúvida, há uma forte relação desses enquadres que se reproduzem sintomaticamente no trote, abrindo para essa prática caminhos para a barbárie. 


\section{TROTE E RAZÃO INSTRUMENTAL}

Durante a observação do trote de Medicina, um jovem desse curso que acompanhava a prática com entusiasmo se aproximou e perguntou em um tom de humor: "Vocês vieram fiscalizar?" [sic]. Respondemos: "Eu acho que vocês não precisam disso, né" [sic]. O estudante, então, replicou: "É. Pode ficar tranquilo. Aqui só tem pessoas racionais e inteligentes" [sic]. Esse diálogo foi um dos pontos mais interessantes da observação, que, de fato, indica que a pessoa que realiza o trote, mesmo com todas as suas problemáticas, pode livremente se autodeclarar inteligente e racional dentro de um processo violento e irracional. A pergunta que se sobressai é: qual a compreensão que esses sujeitos têm acerca da racionalidade?

Como observa Crochík (2011), a ideologia da racionalidade tecnológica auxilia a expressão do preconceito e da violência em sua forma asséptica. A imposição do ajuste pela técnica toma a forma de argumentos racionais, que visam, a princípio, ao aumento da riqueza social e à melhoria das condições de vida, mas que, na verdade, atuam para a adaptação do sujeito a uma sociedade violenta e injusta. Então, pode-se pensar que, no caso do trote - um ritual que, pelos argumentos racionais, celebra a entrada em um curso de nível superior e promove a integração entre alunos -, na verdade, tal prática dissemina a hierarquização e o sadomasoquismo. O paralelo que se traça entre esse tipo de comportamento e o fascismo é que ambos podem ser tidos como racionais, obtendo, por vezes, alguma legitimação cultural. Cabe lembrar que Horkheimer e Adorno (2006) localizam o fascismo na gênese da cultura de uma sociedade administrada, cuja organização econômica e social é o próprio modo de produção. Dessa forma, o fascismo não é um acidente da história e sim o desdobramento desses processos.

A visão de Élcio a respeito da universidade é de que "tem que ser passageira. Você tem que pegar os conhecimentos que você aprendeu aqui e levar pro mercado de trabalho". A frase ilustra o que é uma universidade regida pela lógica de mercado, na qual o ensino, a pesquisa e a extensão estão à mercê do capital e o aluno, futuro profissional, é engrenagem da maquinaria.

Cabe ressaltar que a fala de Élcio remete à ponte que se tem entre o mundo da educação e o mundo do trabalho. Essa relação é especialmente interessante para se pensar o trote, devido ao fato de que o mundo do trabalho capitalista e produtivista é marcado pela relação abusiva patrãoempregado. $O$ que levanta mais camadas para a interpretação de que o trote é a reprodução das relações hierárquicas na universidade e da sociedade, porque, além disso, pode também reproduzir as relações hierárquicas do 
mundo do trabalho, que já exerce força descomunal sobre os sujeitos durante toda a sua formação.

O que se tem, então, é a tendência de racionalizar com um certo cinismo o que - considerando o caráter emancipatório inerente à razão - é irracional. Mauro descreve meticulosamente quais foram os procedimentos tomados no trote, todos os cuidados que tiveram em relação aos calouros, demonstrando uma preocupação metódica. Há uma forte tentativa de mascarar o que há de irracional no trote, de forjar uma ética em uma tradição que, por essência, parece prescindir de ética.

A gente primeiro foi na sala deles conversar né? Falar que o trote não é obrigatório, é só uma forma de desejar boas-vindas a eles e arrecadar dinheiro da festa, que é o principal objetivo. Então a gente foi lá falar que ninguém ia sofrer bullying por causa disso, que na nossa turma teve gente que não participou e nem por isso foi excluído. Falar que é uma brincadeira, que entra quem quer participar da brincadeira. A gente pediu pra trazer protetor solar, trazer roupas velhas pra que não sujassem a que eles tavam na hora. Trazer chinelo pra não queimar os pés. Aí durante o trote, foi comprado água, levaram protetor solar. Que o trote foi realizado de manhã, nove horas. Pra você ver que não é só que a gente não quer maltratar ninguém (Mauro).

Em síntese, como o trote não é obrigatório, sugere-se que o calouro se submeta voluntariamente ao processo de humilhação com alguma promessa de acolhimento por parte dos veteranos e que todos estão de comum acordo contra qualquer atividade que possa levar a agressões extremas. Argumentos formais e procedimentos técnicos para cuidar dos corpos e preservá-los são o suficiente para chamarem-se racionais e inteligentes. No plano das relações, agarram-se ao modelo sadomasoquista, ainda predominante em nossa sociedade.

\section{TROTE, DINÂMICA SADOMASOQUISTA E TRAÇOS DE NARCISISMO DE GRUPO}

Dada a ênfase na hierarquização e na desigualdade evidenciadas nas entrevistas, cabe agora identificar quais são os modelos dinâmicos e as lógicas que regem a prática do trote. Quando questionado sobre a possibilidade de um indivíduo que não participou como calouro do trote participar como veterano, Mauro respondeu:

Eu acredito que, pra você aplicar o trote em alguém, você tem que participar. Porque isso é um ritual. Uma tradição. Não faz sentido tá lá brincando com o calouro se você não passou por aquilo. Não é uma forma de vingança, mas é, porque você já sentiu (Mauro). 
Tem-se então uma norma estabelecida e compartilhada pelo grupo de que só pode participar do trote, como veterano, quem também participou como calouro. A lógica sadomasoquista parece evidente. A entrevistada Paloma falou sobre a festa que foi realizada com o dinheiro arrecadado no trote, especificando que os calouros que não participaram do trote teriam de pagar para entrar.

Quem não participou do trote não tinha direito a entrar de graça na calourada. Achei injusto, porque se eu não quero participar do trote eu não quero participar do trote. Mas se eu quero participar da calourada... Eu sou caloura. O que me impede de participar da calourada? As pessoas reagiram com raiva. Não sei se foi só por causa disso, mas muita gente não foi (Paloma).

Neste caso, a festa adquire o papel de recompensa para aqueles que se submeteram ao trote e também como uma espécie de punição para quem não participou. Assim, torna-se difícil concordar com a narrativa de que o trote tem por objetivo final a integração, tendo em vista que serve não somente como rito de passagem, mas como uma espécie de teste sistemático, com os próprios meios de recompensa e punição, como é ilustrado pela fala acima.

É um evento em que as pessoas vão se conhecer. Mantendo sempre essa hierarquia veterano-calouro. [...] Algumas pessoas acham ruim. É baderna, é sujeira. Mas é aquele momento. Se as coisas forem muito certinhas você não cria um laço com as pessoas. É um momento de você se identificar com seus veteranos (Élcio).

A frase pronunciada por Élcio, "Se as coisas forem muito certinhas você não cria um laço com as pessoas", carrega um significado bem expressivo para se pensar o trote. Estabelece uma relação de causalidade entre as experiências negativas e o vínculo que se cria a partir destas entre as pessoas, ou o grupo. É possível encontrar caminhos que aproximem essa lógica ao que Adorno et al. (1950) identificou como uma das características que compõe a personalidade autoritária. $\mathrm{O} 44^{\circ}$ item da escala F-“Ninguém nunca aprendeu nada realmente importante senão pelo sofrimento"4 $($ p. 255) - representa a ideia de que o sofrimento é uma condição necessária, inevitável e que precisa necessariamente existir para que haja aprendizagem. No caso, é a mesma lógica apresentada por Élcio, porém, o objetivo não é aprender e sim "criar laços".

Além do sadomasoquismo identificado, evidenciaram-se também traços de narcisismo de grupo. Durante a observação do trote de Medicina, gritos de guerra como "1, 2, 3, 4, a medicina é um barato; 4, 3, 2, 1 mas nãoé pra qualquer um" indicam a necessidade de firmar uma supremacia do curso em 
questão, enfatizando a dificuldade de estar nele e o quanto é difícil entrar e possivelmente difícil se manter. "Acetilcolina, eu estudei e passei em medicina", outro grito de guerra repetido inúmeras vezes durante o trote. Celebra o caráter meritocrático do ingresso dos alunos no curso e emprega a palavra "acetilcolina" de uma forma que parece não exercer nenhuma função a não ser de um termo codificante, intencionalmente restrito somente para quem supostamente estudou o suficiente para estar no curso.

Este é um desdobramento de uma vida danificada pela razão instrumental e submetida às demandas do capital. Esses desdobramentos produzem sujeitos com o ego fragilizado e incapazes de pensar criticamente. Quando analisamos esse cenário sob a ótica psicanalítica, torna-se compreensível o motivo pelo qual essa violência - que é institucional e simbólica, mas que é sentida com toda sua intensidade - precisa ser escoada e investida em algo. Como aponta Crochík (2001, p. 94), “os desejos e as características narcisistas e sadomasoquistas, que podem estar associados com a defesa ideológica da técnica, implicam as configurações individuais necessárias para a reprodução social". E o trote, de modo geral, parece completamente alinhado a essa finalidade e perfeitamente a serviço dela.

\section{CONSIDERAÇÕES FINAIS}

Foi possível identificar no trote a predominância de elementos existentes em nosso modelo de sociedade, como a hierarquização e a razão instrumental. Quanto aos indivíduos entrevistados, percebemos o ressentimento para com a universidade e as relações nela estabelecidas, além da predominância de uma dinâmica sadomasoquista e de traços de narcisismo de grupo durante a realização do trote. Estas são algumas nuances de uma prática muito antiga e complexa sendo reproduzida em um contexto específico, que consequentemente deixa impressos todos os aspectos sociais e culturais da região. Se o trote proporciona algum tipo de integração e aprofundamento de laços entre os membros da instituição, isso definitivamente se dá por meio de uma violência que garante a continuidade de um processo que se encontra no seio da própria sociedade. Ao contrário do que podia se esperar, os entrevistados não demonstraram sentidos elaborados acerca do trote, pareciam inclusive refletir pela primeira vez sobre essa prática durante a realização das entrevistas. Isso revela um forte automatismo, que é um dos pontos de aproximação desse rito com o fascismo, tal como afirmou Adorno (2003).

Existem alguns aspectos que ainda acreditamos que merecem maior atenção sobre o tema do trote, como uma tentativa desesperada de 
produzir algum sentimento de pertencimento ao grupo e à comunidade geral. Essa preocupação se deve à percepção de que muitos alunos não são naturais de Boa Vista e esta tem como uma de suas características o intenso fluxo migratório. Também cabe considerar que o estado faz fronteira com dois outros países. Pode, deste modo, haver uma relação entre os desafios para o estabelecimento de vínculos e a submissão ao trote como promessa de integração.

Por fim, é necessário apontar que nem todos os cursos da UFRR se utilizam do trote como recurso de recepção de calouros. O Instituto Insikiran de formação superior indígena não apresenta nenhum tipo de trote nos três cursos que oferta, e, por esse motivo, seus alunos não participaram das entrevistas. Entretanto, cabe aqui alguns apontamentos. Não realizar algum tipo de trote não significa que os alunos ingressantes perdem a oportunidade de participar de uma recepção elaborada por outros membros do Instituto. Todos participam de uma celebração, junto aos colegas que se encontram em períodos mais avançados, que tem por objetivo uma apresentação geral, a troca de experiências, a criação de laços, o que permite aos "calouros" serem bem recebidos em uma nova etapa de suas vidas. É significativo apontar essa diferença, pois, se há relações entre o modelo de sociedade em que vivemos e o trote, também há entre o modelo de comunidades indígenas e a recepção dos calouros no Insikiran. Essa breve comparação nos permite questionar, no âmbito da ética, do respeito ao outro e das relações humanas, em que aspecto a sociedade administrada vem fracassando sistematicamente, tanto nos processos formativos quanto na produção de espaços de esclarecimento.

Artigo recebido em: 16/04/2018

Aprovado para publicação em: 30/06/2018

\section{THE ENDURANCE OF UNIVERSITY'S HAZING AND VIOLENCE IN THE EDUCATIONAL} CONTEXT.

ABSTRACT: This paper aims to understand how university hazing rituals occurs in the Federal University of Roraima (UFRR). It's based on the perspective of the Critical Theory. Observations were performed to gather data at medical and civil engineering schools and interviews with students who have participated in university's hazing as well. We verified that the hazing seeks, in some level, to fit the traditional model of hazing (marked by the vexatious situations, psychological violence, etc.) and the reasons why this practice is defended are mainly linked to the adhesion to the group. The results of this research allowed to create an entanglement between questions 
that, when superficially analyzed, seem to have no immediate connection, but cannot be ignored to understand the university's hazing culture.

KEYwords: Hazing. University. Violence. Group.

\section{LA PERSISTENCIA DE LAS NOVATADAS Y DE LA VIOLENCIA EN EL CONTEXTO EDUCACIONAL.}

RESUMEN: El objetivo de este artículo es comprender cómo ocurren las novatadas realizadas en la Universidad Federal de Roraima (UFRR). Es guiado por la perspectiva de la Teoría Crítica de la Sociedad. Para la recolección de datos se realizaron observaciones en novatadas de los cursos de medicina e ingeniería civil y entrevistas con estudiantes que ya participaron de la novatada. Constatamos que la novatada busca, en cierta medida, acomodarse al modelo tradicional de la novatada (marcado por las situaciones vejatorias, violencia psicológica, etc.) y los motivos por los cuales esta práctica es defendida están principalmente vinculados a la adhesión del individuo al grupo. Los resultados permitieron la producción de un enredo entre cuestiones que, superficialmente, parecen no tener conexiones directas, pero que no pueden ser ignoradas para comprender la cultura de la novatada en el contexto de la universidad.

Palabras clave: Novatada, Universidad. Violencia. Grupos.

\section{NOTAS}

1 "Dois calouros são hospitalizados em coma alcoólico após trote em RR". Notícia publicada no portal de notícias G1 em 12 de maio de 2014. Disponível em: http:// g1.globo.com/rr/roraima/noticia/2014/05/dois-calouros-sao-hospitalizados-em-coma-alcoolico-apos-trote-em-rr.html. Acesso em: 19 set. 2017.

2"UFRR divulga nota oficial de repúdio a trotes abusivos". Disponível em: http://ufrr. br/dzo/index.php?option=com content\&view=article\&id=70:ufrr-divulga-nota-oficial-de-repudio-a-trotes-abusivos\&catid=18\&ltemid=232. Acesso em: 4 ago. 2017. 3 "O trote universitário na Universidade Federal de Roraima e seus processos psicossociais subjacentes", uma ramificação do projeto intitulado "Individuação e barbárie: manifestações da violência no processo de constituição da subjetividade em Boa Vista - Roraima".

4 "Nobody ever learned anything really important except through suffering... O item da escala se encontra na categoria de submissão autoritária, que busca exprimir aspectos de submissão e atitudes não criticas em relação aos modelos de autoridade presentes no endogrupo. 


\section{REFERÊNCIAS}

ADORNO, T. W.; FRENKEL-BRUNSWIK, E.; LEVINSON, D. J.; SANFORD, R. N.. The authoritarian personality. New York: Harper \& Brothers, 1950.

ADORNO, T.W. Educação e emancipação. 3. ed. São Paulo: Paz e Terra, 2003.

. Minima Moralia - reflexões a partir da vida lesada. Rio de Janeiro: Beco do Azougue, 2008.

BUENO, Sinésio Ferraz. Vida danificada e trote universitário. Educação em Revista, n.6, p.37-50, 2005.

CROCHIK, José Leon. Teoria crítica da sociedade e estudos sobre o preconceito. Revista Psicologia Política, n. 1, p. 67-99, 2001.

. Teoria Crítica da Sociedade e psicologia: alguns ensaios. Brasília: CNPq, 2011.

FREUD, Sigmund. Além do princípio do prazer, psicologia de grupo e outros trabalhos. Rio de Janeiro: Imago, 1977.

. O mal-estar na civilização. São Paulo: Abril Cultural, 1978.

HORKHEIMER, Max. Teoria Tradicional e Teoria Crítica. In: HORKHEIMER, Max; ADORNO, Theodor W. Textos escolhidos. 5. ed. São Paulo: Nova Cultural, 1991.

HORKHEIMER, Max; ADORNO, Theodor W. Temas básicos da sociologia. São Paulo: Cultrix, 1978.

. Dialética do Esclarecimento: fragmentos filosóficos. Tradução de Guido Antonio de Almeida. Rio de Janeiro: Jorge Zahar, 2006.

MARCUSE, Herbert. A ideologia da sociedade industrial - O homem unidimensional. Rio de Janeiro: Zahar Editores, 1979.

RISTOFF, Dilvo; Jaime, GIOLO. Educação Superior Brasileira: 1991-2004. 28. ed. Brasília: Instituto Nacional de Estudos e Pesquisas Educacionais Anísio Teixeira, 2006.

SAVIANI, Dermeval. Escola e democracia. 42. ed. Campinas: Autores Associados, 2012.

SILVA, Pedro Fernando da. A liberdade sexual administrada: contribuição à crítica do conformismo. Curitiba: Juruá, 2010.

TRAGTENBERG, Maurício. A delinquência acadêmica. In: Sobre educação, política e sindicalismo. São Paulo: Editora UNESP, 2004.

TRIVIÑOS, Augusto Nibaldo Silva. Introdução à pesquisa em ciências sociais: a pesquisa qualitativa em educação. São Paulo: Atlas, 1987.

UFRR. Conselho Universitário. Resolução n²6/2003-CUNI. Aprova o novo estatuto da Universidade Federal de Roraima. Boa Vista, RR, 31 dez. 2003.

VASCONCELOS, Paulo. A violência no escárnio do trote tradicional: um estudo filosófico em antropologia cultural. Santa Maria: Universidade Federal de Santa Maria, Santa Maria. 1993. 
ZUIN, Antônio Álvares Soares. O trote na universidade: passagens de um rito de iniciação. São Paulo: Cortez, 2002.

. O trote universitário como violência espetacular. Educação e Realidade, v. 36, p. 587-604, 2011.

Carlos Eduardo Ramos: Mestre em Psicologia Escolar e do Desenvolvimento Humano pela Universidade de São Paulo. Professor do curso de Psicologia da Universidade Federal de Roraima.

E-mail: carlos.ramos@ufrr.br

Caobe Lucas Rodrigues de Sousa: Estudante do curso de Psicologia da Universidade Federal de Roraima.

E-mail: caobeee@hotmail.com 